\title{
Latest Achievements in Polymer Optical Fiber Gratings: Fabrication and Applications
}

\author{
Rui Min ${ }^{1, *} \mathbb{C}$, Beatriz Ortega ${ }^{1}$ and Carlos Marques ${ }^{2}(\mathbb{C}$ \\ 1 ITEAM Research Institute, Universitat Politècnica de València, Camino de Vera, s/n 46022 Valencia, Spain; \\ bortega@dcom.upv.es \\ 2 I3N\& Physics Department, Universidade de Aveiro, Campus Universitário de Santiago, 3810-193 Aveiro, \\ Portugal; carlos.marques@ua.pt \\ * Correspondence: rumi@doctor.upv.es; Tel.: +34-96-387-0000
}

Received: 18 February 2019; Accepted: 26 March 2019; Published: 29 March 2019

\begin{abstract}
Grating devices in polymer optical fibers (POFs) have attracted huge interest for many potential applications in recent years. This paper presents the state of the art regarding the fabrication of different types of POF gratings, such as uniform, phase-shifted, tilted, chirped, and long period gratings, and explores potential application scenarios, such as biosensing and optical communications.
\end{abstract}

Keywords: polymer optical fibers; gratings devices; optical filters; fiber sensing

\section{Introduction}

Polymer optical fibers (POFs) show attractive characteristics when compared with silica fibers, such as low Young's modulus, high failure strain, high flexibility, and bio-compatibility [1]. Different kinds of plastic material with unique advantages can be used for POF fabrication besides polymethyl methacrylate (PMMA), which is the most common material with a low cost [2]. Examples of these materials are low water absorption cyclic olefin copolymers (TOPAS) [3], high glass transition temperature cyclic-olefin polymer (ZEONEX) [4], excellent clarity and impact strength engineering plastic (Polycarbonate) [5], biodegradable and biocompatible poly(D,L-lactic acid) (PDLLA) [6], and low-loss cyclic transparent amorphous fluoropolymers (CYTOP) [7]. In addition to fiber materials, several types of POFs are available in the current market with different core sizes and structures, such as small-diameter step-index (SI) POF, small-diameter microstructure POF, commercial grade-index (GI) POF, and commercial large-diameter PMMA POF, as shown in Table 1. Extended reviews about the potential applications of these fibers can be found in the literature as follows. Koike et al. [8] reviewed the status of POFs and achievements on GI POF as a promising candidate for the next generation of optical fibers. Zubia et al. [9] reviewed the most significant features of POFs, including the main types, manufacturing, and potential applications in 2001. Polishuk [10] gave a view about potential large-core POF for low-bit-rate and short distance applications. Micro-structured polymer optical fibers (mPOF) were inspired by photonic crystal fibers, first invented by Knight et al. [11] in 1996; Argyros et al. [12] proposed new potential applications for these POF structures, and also showed their easier single-mode performance compared with step-index POFs, due to the fabrication process.

Due to increasing numbers of emerging services, such as intelligent home systems, visible light communications, etc., in indoor networks, the increase of high-capacity demand shifts from long-haul systems to short-range communication links. Indeed, POFs are good candidates for short-range communications [13-21], with low weight and high transmission capacity. Accordingly, Professor Koike and his research group demonstrated data transmission over POF in 1995 [22], where they reported $2.5 \mathrm{~Gb} / \mathrm{s} 100 \mathrm{~m}$ data transmission using GI POF at $650 \mathrm{~nm}$ wavelength; more recently, in 2016, they developed $120 \mathrm{~Gb} / \mathrm{s}$ GI POF, as well as the ballpoint pen interconnection technology 
for uncompressed $4 \mathrm{~K} / 8 \mathrm{~K}$ video transmission [23]. Recent achievements in POF-based transmission networks have led to promising applications in future home networks, such as Pinzon et al. [24], where a five-channel visible wavelength-division multiplexing (WDM) system was transmitted over 50-m step index POF links with a $2 \mathrm{~Gb} / \mathrm{s}$, bidirectional, real-time link. Moreover, Osahon et al. [25] has demonstrated gigabit-per-second transmission over a short-range step-index POF using a multilevel pulse amplitude modulation (PAM-M) scheme, based on a laser diode (LD) as the optical source, which also shows successful simultaneous transmission of 16-QAM $40 \mathrm{MHz}$ bandwidth wireless local area network (WLAN) and 64 quadrature amplitude modulation (QAM) long term evolution (LTE-A) bands. Among recent achievements, Forni et al. [26] must be highlighted, due to their simultaneous transmission of an IEEE 02.11n 16-QAM 40 MHz bandwidth WLAN, 964 QAM LTE-A bands, and $1.7 \mathrm{~Gb} / \mathrm{s} 4$-PAM baseband signals over $50 \mathrm{~m}$ of 1-mm core diameter GI POF for in-home networks.

Table 1. Typical polymer optical fiber (POF) structures.

\begin{tabular}{|c|c|c|c|}
\hline Fiber Type & Transversal Section & Diameter & Main Feature \\
\hline $\begin{array}{l}\text { Small-diameter step-index } \\
\text { (SI) POF }\end{array}$ & & $100 \sim 200 \mu \mathrm{m}$ & $\begin{array}{l}\text { Easy coupling } \\
\text { Potential single-mode performance }\end{array}$ \\
\hline Microstructure POF & & $100 \sim 250 \mu \mathrm{m}$ & $\begin{array}{l}\text { Easy to obtain single-mode } \\
\text { performance } \\
\text { Can be made with a single material }\end{array}$ \\
\hline $\begin{array}{l}\text { Commercial grade-index } \\
\text { (GI) POF }\end{array}$ & & $490 \mu \mathrm{m}$ & $\begin{array}{l}\text { Low loss } \\
\text { Large bandwidth }\end{array}$ \\
\hline $\begin{array}{l}\text { Commercial large-diameter } \\
\text { polymethyl methacrylate } \\
\text { (PMMA) POF }\end{array}$ & & $1 \mathrm{~mm}$ & $\begin{array}{l}\text { Low price } \\
\text { Easy handling }\end{array}$ \\
\hline
\end{tabular}

Sensing is also an emerging area of POF applications under research, as stated in the extensive literature. Peters et al. [27] presented a review work focused on strain and temperature sensing applications, based on POFs using different solutions. POF-based sensing techniques can be classified on intensity modulation sensing, Brillouin scattering, and wavelength sensitivity grating devices. Bilro et al. [28] presented a review paper about intensity modulation sensing, where all sensors include a light source, an optical fiber, and an optical spectrum analyzer or a photodetector when the accuracy is not so critical, such as structural health monitoring [27,29], deformation monitoring [30], medical instrument [31-34], environment monitoring [35,36], mechanical measurement [37-39], and chemical detection [40,41]. The second technique, based on Brillouin scattering in POFs [26], is mainly focused towards distributed sensing, such as structural health monitoring by POF strain sensor technology [42], according to the fundamental properties of Brillouin scattering in POF as reviewed by Mizuno et al. [43]. 
The last technique, based on wavelength sensitivity grating devices, is the most promising area for POF sensing. In contrast with the applications of grating devices in silica fiber, which have been under intense research for more than 30 years [44], the first POF Bragg grating (POFBG) was demonstrated by Peng's group in 1999 [45]. Since then, the literature has presented a large number of papers reporting significant achievements, such as Dobb et al.'s [46] report in 2005 on the first FBG in few mode and endlessly single mode mPOFs, using a continuous wave laser at $325 \mathrm{~nm}$ wavelength; the first ultraviolet (UV) inscription of Long Period Grating in POFs published by Saez et al. [47] in 2010; or the first FBG in multimode POF at $827 \mathrm{~nm}$ wavelength, published by Johnson et al. [48] in 2010.

The main drawback of PMMA fibers is water absorption, which can be reduced by using other polymer materials. An example is TOPAS, a cyclic olefin copolymer with moisture absorption that is at least 30 times lower than that of PMMA. In this sense, Wu et al. reported the first experimental results about a humidity-insensitive POF Fiber Bragg Grating [49]. Moreover, Woyessa et al. [4] demonstrated the very first low, endlessly single-mode and humidity-insensitive mPOF made of ZEONEX-grade 480R with a glass transition temperature of $138^{\circ} \mathrm{C}$, and the first FBG was inscribed in ZEONEX mPOF at a low-attenuation $850 \mathrm{~nm}$ region. Polycarbonate is another material, first introduced by Fujitsu in 1989 [50], which exhibits excellent transparency and impact strength. Fasano et al. [5] reported the first experimental demonstration of an endlessly single-mode polycarbonate MPOF, and also inscribed the first FBG in polycarbonate mPOF. Last but not least, cyclic transparent fluoropolymers (CYTOP) exhibit excellent transmission characteristics from the visible to near-infrared spectrum, due to the optical absorption wavelength shift to $7.7 \sim 10 \mu \mathrm{m}$, which exceeds the transmission limit of other polymer materials, such as high-loss PMMA, induced by the high overtone vibration of $\mathrm{C}-\mathrm{H}$ at $3 \sim 3.5 \mu \mathrm{m}$. This, therefore, allows Bragg gratings to be inscribed in CYTOP fibers by using a femto-second laser [51-56] and phase mask method [57-59].

As happens in silica fibers, special grating devices are attractive for a variety of applications. Birefringent gratings have been employed to change the polarization state of light at different wavelengths $[60,61]$, and laser micromachining has been used for obtaining POF gratings with different microstructures in the cladding, in order to enhance their humidity response time [62] with a high strain sensitivity [63]. A Fabry-Perot cavity based on POF gratings was fabricated by Dobb et al. [64], phase-shifted (PS) FBGs in POF were obtained by uniform UV exposure of the central part of 1-cm-long gratings [64], and tilted FBGs were reported by Hu et al. in 2014 [65] in step-index POFs, among others included in [66]. Finally, chirped FBGs were fabricated by using a chirped phase mask in 2017 [67].

Previous literature includes extensive reviews published by Webb [1], Luo et al. [66], Canning [68], Marques et al. [69,70], Broadway et al. [71], Berghmans et al. [72], and Nogueira et al. [73], focusing on the uniform POF gratings fabrication and applications. Due to the emerging POF applications in communications and sensing, intense work has been done in recent years towards obtaining a short, flexible, and reliable fabrication process for gratings in these fibers.

After discussing historical records and motivation in the introduction section of this paper, we report below a review work about the latest results on POF grating device fabrication and applications, structured as follows. Recent results on POF gratings fabrication using different UV lasers and fibers will be reported in Section 2, and Section 3 will focus on recently identified potential applications of different POF grating devices. Finally, Section 4 summarizes the main conclusions and outlines the most promising POF gratings research lines, to be followed within the short- and mid-term.

\section{Fabrication of Polymer Optical Fiber Gratings}

POF Bragg gratings (POFBGs) are typically fabricated by direct writing [74], Sagnac interferometry [75], and phase mask [1] techniques, although the preferred POFBG fabrication technique is the latter one, due to easy implementation in spite of the limited flexibility. Direct writing provides flexibility in terms of structure and wavelength, but the femtosecond laser system is required for FBG irradiation, and the resolution imposes limitations on the achievable low wavelengths. 
Long period gratings are usually obtained by direct writing [75,76], heat imprinting, and amplitude masks $[77,78]$.

In this section, we present the recent achievements in the optimization of the fabrication process, as well as gratings inscription in different types of doped and undoped POFs, and illustrate the flexibility of the fabrication procedures.

\subsection{Optimization of the Fabrication Process}

Gratings are fabricated in fibers, due to the photosensitivity of polymer material under UV, which leads to the fiber refractive index change after UV absorption. Indeed, photosensitivity strongly depends on the wavelength and the inscription mechanism, as was completely detailed by Luo et al. [66]. Since the Bell laboratories discovered this around 1970s [79], the absorption of $325 \mathrm{~nm}$ wavelength UV radiation was identified as the preferred technique for refractive index change in PMMA material. Depending on the power and wavelength of the absorbed light, several mechanisms occur in combined reactions, such as photo polymerization, photo degradation, and cross-linking change between the polymer chains. Yu et al. [80] reported refractive index modification by photo-isomerization, and also showed that polymer fiber cores doped with dopants (i.e. trans-4-stilbenemethanol, or TS) exhibit different refractive index changes under UV radiation. Saez et al. [81] reported that the photosensitivity of undoped PMMA mPOF can be increased by straining the fiber during photo inscription, which is evidence of photodegradation and paved the way for undoped PMMA POF grating irradiation under $325 \mathrm{~nm}$ wavelength.

The stability of POF gratings is a critical issue mentioned by several papers $[67,82-85]$. Pre-annealed POFs allow the fabrication of more stable short-term performance gratings at both greater strain and higher temperatures [85]. However, both non-annealed and annealed TS-doped polymer optical fibers were studied in terms of FBG stability, and the post-inscription thermal annealing process was necessary to produce stable gratings [83]. POF grating fabrication has been reported using different lasers, such as an $800 \mathrm{~nm}$ Ti:sapphire fs laser system [74,86], a $532 \mathrm{~nm}$ Nd:YVO4 laser system [77,87], a $387 \mathrm{~nm}$ Ti:sapphire fs laser system [88], a $355 \mathrm{~nm}$ Nd:YAG laser [89], a $325 \mathrm{~nm}$ optical parametric oscillator (OPO) pulsed laser, a dye laser, an He-Cd laser [81,90-95], and a $248 \mathrm{~nm} \mathrm{KrF}$ excimer laser system $[73,96]$. Although $325 \mathrm{~nm}$ was the first irradiation wavelength reported by Peng's group [45], and initially $248 \mathrm{~nm}$ wavelength was not considered suitable for polymer fiber Bragg grating writing, due to high absorption, the first successful Bragg grating inscription in 30 seconds using low flow and a repetition rate at $248 \mathrm{~nm}$ UV light opened a new field of interest for grating irradiation [96]. Since then, the research work on gratings inscription using $248 \mathrm{~nm}$ wavelength has been continuously growing. A typical POF FBG irradiation system is shown in Figure 1, where the pulse power and repetition rate can be optimized $[97,98]$ in order to shorten the fabrication time, as will be shown below.

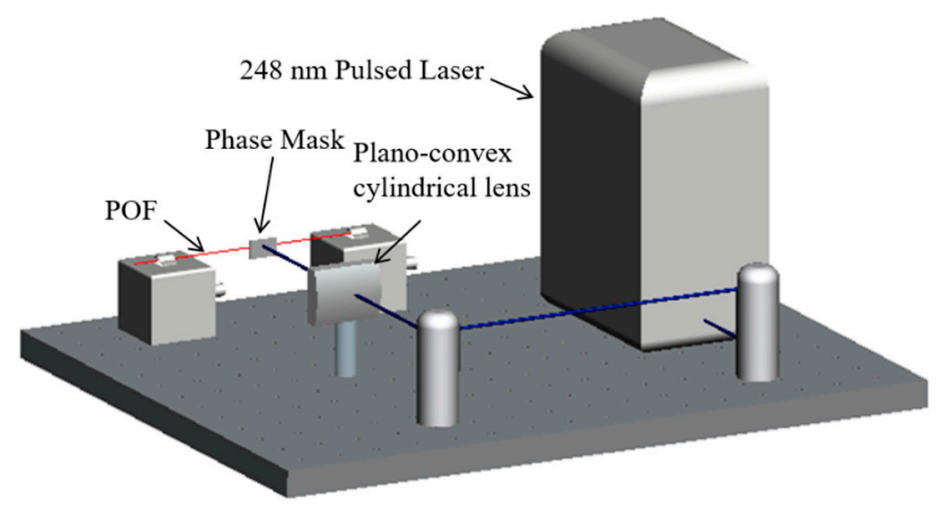

Figure 1. Typical POF FBG irradiation system; image adapted from [58]. 


\subsection{Different Polymer Materials}

Due to the low photosensitivity of pure PMMA fiber [93], doped POFs have attracted researchers' interest $[80,98,99]$. Peng's group employed a step-index, multimode PMMA fiber with an organic dye doped core [100] for grating irradiation under a $325 \mathrm{~nm}$ UV beam, and obtained seven peaks in the reflected spectrum. The same group fabricated another fiber with low-concentration ethyl and a benzyl methacrylate doped core, which led to obtaining a $-28 \mathrm{~dB}$ transmission FBG with 85 min exposure [90]. Tam's group investigated a step-index PMMA POF with a TS (1\% w.t.) and diphenyl sulfide (DPS) (5\% mole) doped core (diameter of $8.2 \mu \mathrm{m})$, as well as pure PMMA cladding (diameter of $150 \mu \mathrm{m}$ ). Both dopants were used to increase the refractive index and enhance photosensitivity [80], and they obtained one FBG of about $-10 \mathrm{~dB}$ transmission after $10 \mathrm{~min}$. Saez et al. [93] reported a highly photosensitive mPOF using Benzyl dimethyl ketal (BDK) as a dopant in the core, and $-23 \mathrm{~dB}$ transmission was achieved after $13 \mathrm{~min}$, since the lack of extra dopants required to compensate for the index reduction allows for shorter times compared with BDK-doped step-index fiber [99]. Recently, $\mathrm{Hu}$ et al. [101] improved the fiber drawing technology with selected center-hole BDK doping in $\mathrm{mPOF}$, for a rapidly growing process with $83 \%$ reflectivity in $40 \mathrm{~s}$. Tam's group investigated a new dopant material, diphenyl disulphide, which enables a fast and positive refractive index change with a low ultraviolet dose, and leads to Bragg gratings fabrication after just 7 ms under 325 nm-wavelength UV signal irradiation [102].

Pospori et al. [84] and Pereira et al. [103] fabricated FBGs in BDK-doped POF using $248 \mathrm{~nm}$ and $266 \mathrm{~nm}$ wavelength irradiation, respectively, and obtained strong POFBGs with a single short laser pulse (15 and 8 ns of duration), as shown in Figure 2, which is even compatible with the fiber drawing process. Bragg gratings inscription in the $850 \mathrm{~nm}$ spectral region was also reported by using step-index PMMA POF irradiation, using a $248 \mathrm{~nm}$ krypton fluoride $(\mathrm{KrF})$ excimer laser system, which only took 0.4 seconds with $100 \mathrm{~Hz}$ pulse repetition, as shown in Figure 3. In this fiber, the cladding material is pure PMMA, while the core is PMMA doped with TS (1\% w.t.) and diphenyl sulfide (DPS) (5\% mole) to enhance the photosensitivity and increase the refractive index [98].

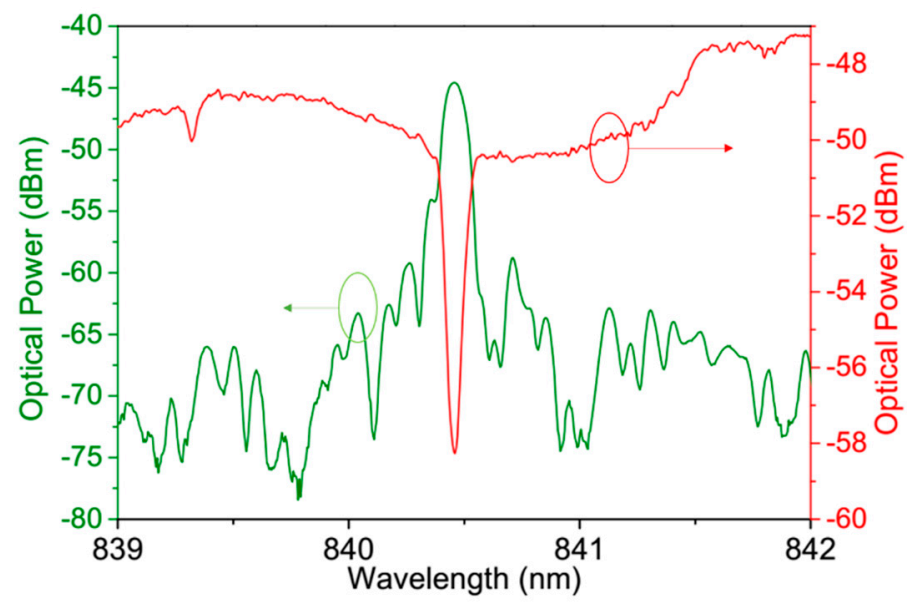

Figure 2. Transmission and reflection spectrum of Fiber Bragg Grating in BDK-doped micro-structured polymer optical fiber (mPOF) with one single $266 \mathrm{~nm}$ wavelength pulse; image adapted from [103].

Marques et al. [104] reported the inscription of gratings in POFs made of different materials (TOPAS, ZEONEX, and Polycarbonate) under $248 \mathrm{~nm}$ wavelength, and compared it with the same fiber irradiation under $325 \mathrm{~nm}$, resulting in a reduction of the irradiation time by at least 16 times (Table 2) and better stability when $248 \mathrm{~nm}$ wavelength is employed. 


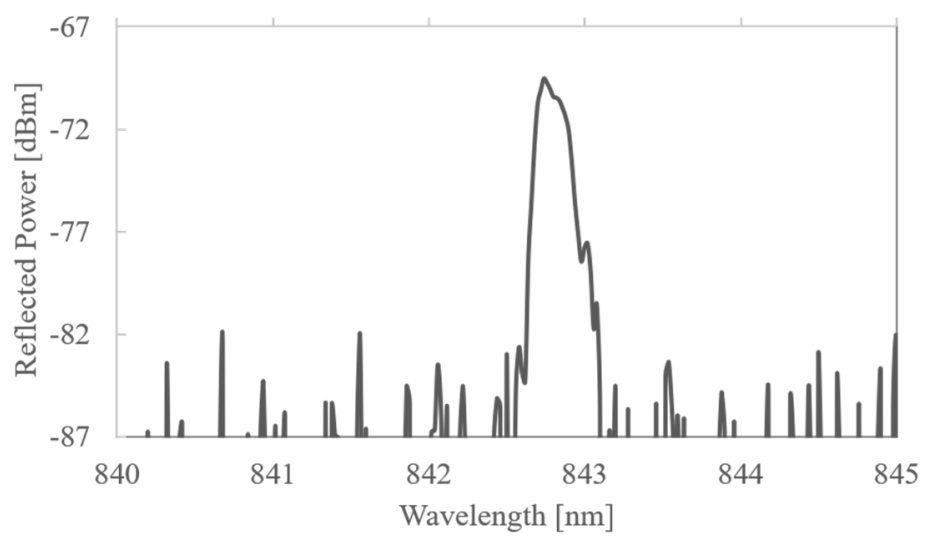

Figure 3. Reflected spectrum of a FBG in a trans-4-stilbenemethanol (TS)-doped, step-index POF, inscribed using a $100 \mathrm{~Hz}$ repetition rate and pulse energy of $0.50 \pm 0.02 \mathrm{~mJ}$ in 0.4 seconds (40 pulses); image adapted from [98].

Table 2. POFBG inscription with pulsed $248 \mathrm{~nm} \mathrm{KrF}$ laser system [104].

\begin{tabular}{lcccc}
\hline POFs & $\begin{array}{l}\text { Inscription Time } \\
\text { (seconds) }\end{array}$ & $\begin{array}{l}\text { FWHM } \\
(\mathbf{n m})\end{array}$ & $\begin{array}{l}\text { Reflection Band } \\
(\mathbf{d B})\end{array}$ & $\begin{array}{l}\text { Optimal Energy } \\
(\mathbf{m} \mathbf{)})\end{array}$ \\
\hline PMMA mPOF & 25 & 0.4 & 32 & 6.0 \\
Topas 8007 mPOF & 25 & 0.6 & 31 & 5.5 \\
Topas 5013 mPOF & 20 & 0.6 & 23 & 6.0 \\
Topas step-index POF & 11 & 0.8 & 31 & 5.0 \\
Zeonex 480R mPOF & 15 & 0.7 & 28 & 3.5 \\
Polycarbonate mPOF & 14 & 0.6 & 23 & 3.0 \\
\hline
\end{tabular}

Min et al. [58] obtained the first $600 \mathrm{~nm}$ wavelength grating with commercial CYTOP POF, using a $248 \mathrm{~nm} \mathrm{KrF}$ laser system with a repetition of $40 \mathrm{~Hz}$ and average pulse energy of $\sim 0.60 \mathrm{~mJ}$ during $\sim 60 \mathrm{~min}$, as shown in Figure 4, with potential applications in the visible range.

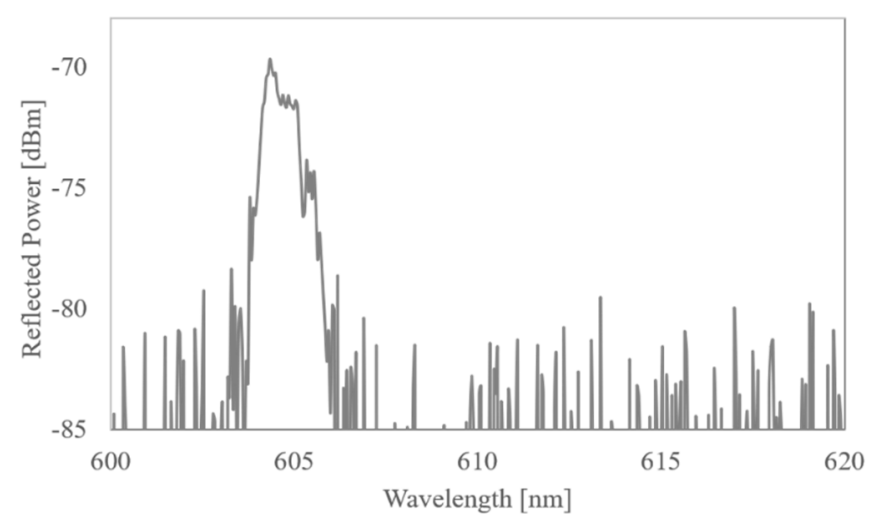

Figure 4. Reflected spectrum of the FBG in cyclic transparent amorphous fluoropolymers (CYTOP) fiber; image adapted from [58].

\subsection{Special Grating Devices}

Recently, a novel bandpass transmission filter based on PS FBG at telecom wavelength [105] was obtained using the Moiré method by $325 \mathrm{~nm}$ Kimmon laser system exposure for about 20 mins, as shown in Figure 5. A Moiré structure is formed by superimposing two gratings of equal amplitude but with slightly different periods. Figure 6a shows the result of two superimposed pulses on a single-mode, BDK-doped mPOF by using a $248 \mathrm{~nm} \mathrm{KrF}$ laser emitting an output pulse power of $2.5 \mathrm{~mJ}$ energy and a $15 \mathrm{~ns}$ duration [106]. The obtained grating showed $0.035 \mathrm{~nm}$ bandwidth and $8 \mathrm{~dB}$ in the rejection band, with a high level of flexibility and no need for strain accuracy. At the $850 \mathrm{~nm}$ 
wavelength region, PS FBG was also obtained directly during the grating fabrication, by placing a narrow blocking aperture in the center of the UV beam (see Figure 6b) [107]. A high-quality Bragg grating structure was obtained with $-16.3 \mathrm{~dB}$ and $-13.2 \mathrm{~dB}$ dips in transmission. The only drawback is one narrow line needing blocking accuracy, which must be put on the phase mask.

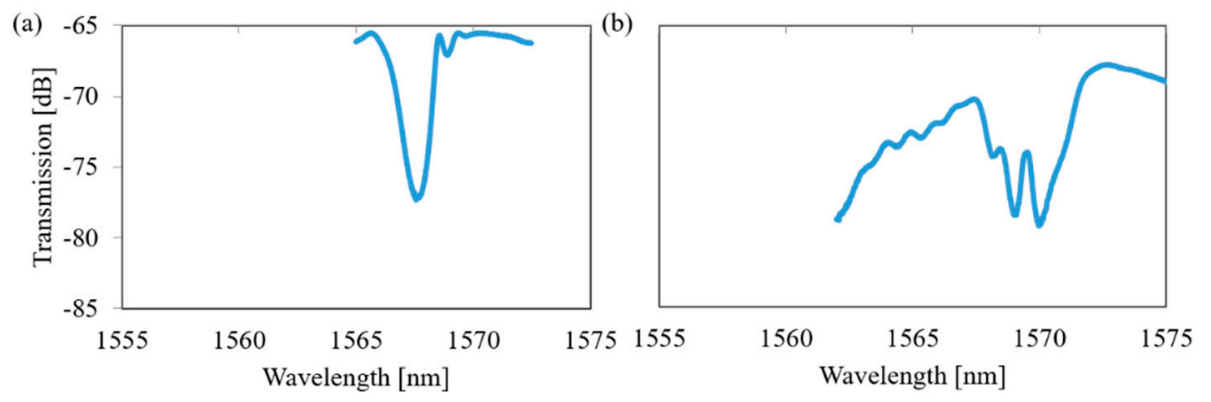

Figure 5. Phase-shifted (PS) FBG fabricated by $325 \mathrm{~nm}$ irradiation: (a) uniform FBG (first fabrication step), (b) PS FBG (Moiré structure based on two overlapped uniform gratings); image adapted from [105].
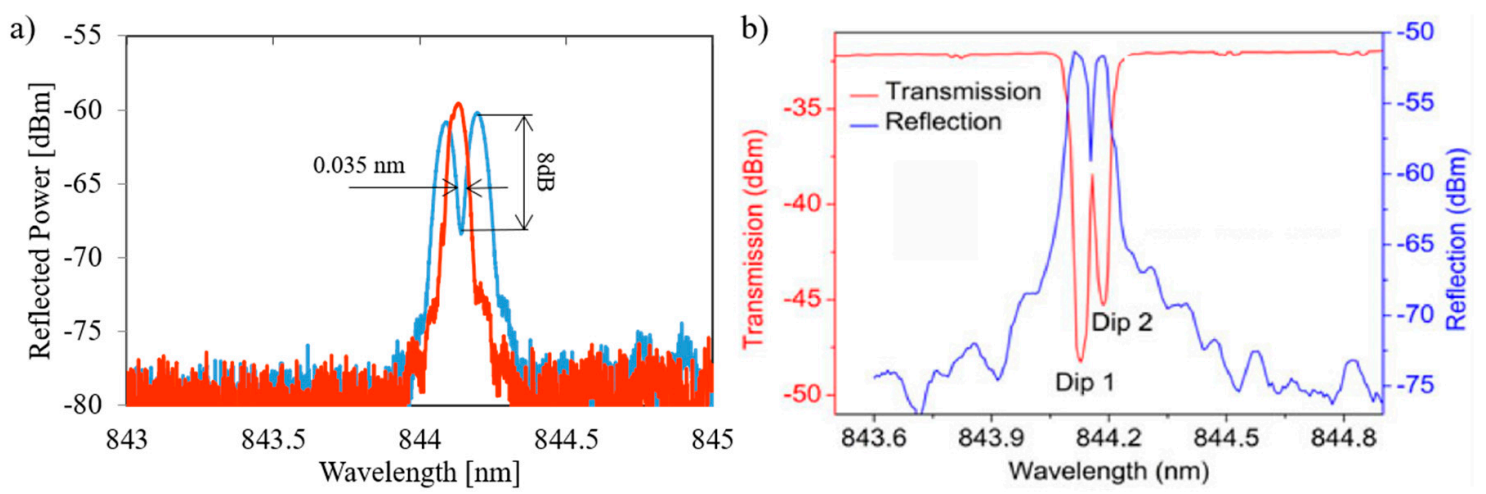

Figure 6. PS-FBG fabrication by $248 \mathrm{~nm}$ irradiation: (a) Moiré overlapping method (image adapted from [106]); (b) a narrow blocking in the center (image adapted from [107]).

Although chirped FBGs in POF were proposed for dispersion tuning without a wavelength shift in 2005 [108], the first chirped FBG in POF was inscribed in 2017 using an KrF excimer laser, operating at $248 \mathrm{~nm}$, and a 25-mm long chirped phase mask, customized for 1550-nm grating inscription [67]. The laser pulse rate was $1 \mathrm{~Hz}(5 \mathrm{~mJ})$, and only a few shots were employed for the grating response depicted in Figure $7 \mathrm{a}$, with a $3.9 \mathrm{~nm}$ bandwidth and $1.2 \mathrm{~nm} / \mathrm{cm}$ chirp. The chirped phase mask method offers significant stability, with high cost and no flexibility as its main drawbacks. Since then, different techniques have been demonstrated to be valid for fabricating chirped gratings in POF. Theodosiou et al. used the femtosecond direct writing method to obtain chirped FBG in commercial CYTOP POF [52], which consisted of 2000 periods, with a total length of $\sim 4.5 \mathrm{~mm}$ and a 10-nm bandwidth (chirp of $\sim 2.22 \mathrm{~nm} / \mathrm{mm}$ ), as shown in Figure $7 \mathrm{~b}$. A femtosecond laser direct writing was used for flexible chirped grating writing, with limitations for low wavelengths. However, the first tunable chirped FBG was fabricated in a tapered, BDK-doped mPOF by using a uniform phase mask under $248 \mathrm{~nm}$ UV [109]. The spectral reflected power of a $10 \mathrm{~mm}$ grating with chirp of $\sim 0.26 \mathrm{~nm} / \mathrm{mm}$ under $1.6 \%$ strain is shown in Figure $7 \mathrm{c}$, and the tunable properties were given by the strain and temperature sensitivity, with $0.71 \pm 0.02 \mathrm{pm} / \mu \varepsilon$ and $56.7 \mathrm{pm} /{ }^{\circ} \mathrm{C}[109,110]$, as shown in Figure 8. However, largely chirped POFBGs have been also fabricated by hot water-assisted gradient thermal annealing, as shown in Figure 7d [111], where one grating with $\sim 1.1 \mathrm{~nm} / \mathrm{mm}$ chirp was obtained. The simplicity of this method is one of its main advantages, since no special phase mask or additional etching are needed, and it enables easy control tuning of the central wavelength and chirp characteristics. 

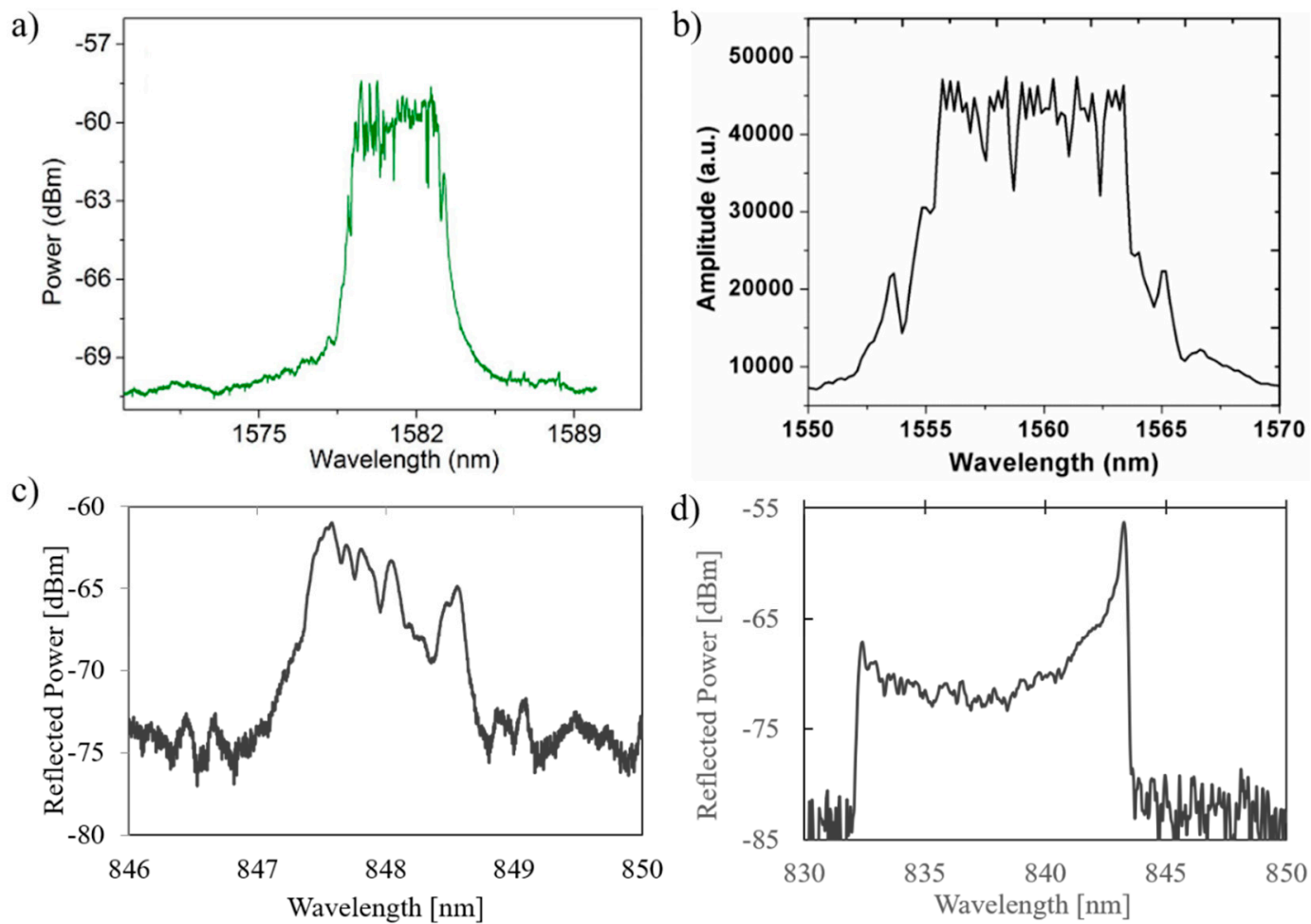

Figure 7. The reflected spectral power of a chirped POFBG fabricated by different techniques: (a) chirped phase mask (image adapted from [67]), (b) femtosecond directly writing on CYTOP POF (image from [65]), (c) under $1.6 \%$ strain with tapering method (image adapted from [109]), and (d) thermal annealing (image adapted from [111]).
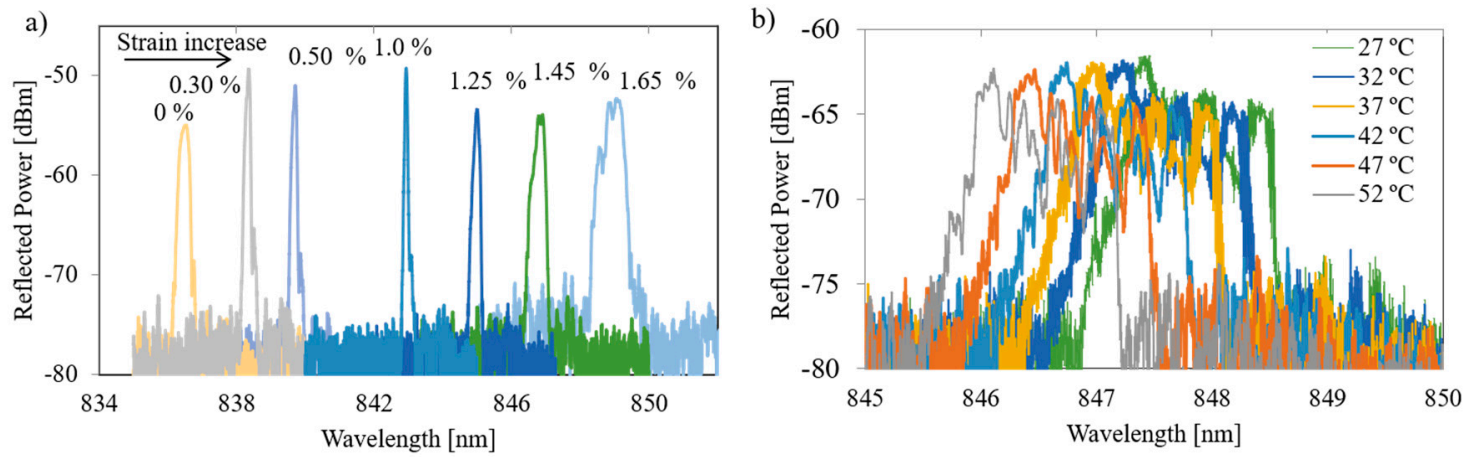

Figure 8. The reflected spectral power of chirped POFBGs (a) under different strain and (b) under different temperatures; image adapted from [109].

Finally, regarding long period gratings in POF, the extensive literature during the last years shows different mechanisms and methods to be used for fabricating them in POF [47,75,76,87,95,112]. Recently, Min et al. [113] demonstrated a $-20 \mathrm{~dB}$ transmission LPG in mPOF (see Figure 9a) using the point-by-point method, with an slit width of $0.2 \mathrm{~mm}$; the beam was shifted $1 \mathrm{~mm}$ for inscribing every point, and 25 steps were completed to obtain an LPG total length of $25 \mathrm{~mm}$. Each inscription point was irradiated by two $15 \mathrm{~ns}$ pulses emitted by the UV laser at $1 \mathrm{~Hz}$ frequency repetition rate, and therefore, a $2 \mathrm{~s}$ irradiation time means a significant reduction from the $42 \mathrm{~s}$ per point writing time reported in a previous work [95]. The strain sensitivity about $-2.3 \pm 0.05 \mathrm{~nm} / \mathrm{mstrain}$ was measured for increasing strain, whereas $-2.25 \pm 0.05 \mathrm{~nm} /$ mstrain was measured for decreasing strain, due to polymer hysteresis, as shown in Figure $9 \mathrm{~b}$; this is slightly larger than the value presented in the previous literature, which ranged from -1.40 to $-1.44 \mathrm{~nm} / \mathrm{mstrain}$ for increasing strain and between -1.30 and $-1.40 \mathrm{~nm} / \mathrm{mstrain}$ for decreasing strain [114]. 

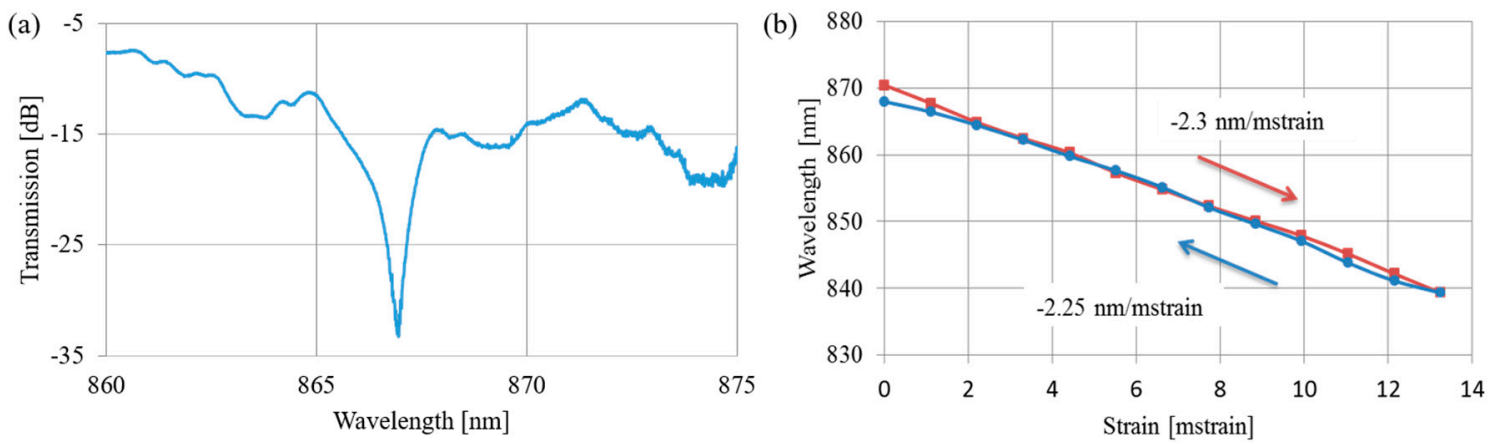

Figure 9. (a) Transmission of Long Period Grating, and (b) wavelength change induced by increasing and decreasing strain; image from [113].

\section{Applications}

Dispersion compensation using chirped POFBG was first proposed in 2005 [107], but the experimental demonstration of a largely tunable dispersive device based on a chirped FBG in $\mathrm{mPOF}$ was published by Min et al. [115]. Figure 10 depicts the reflected spectral power with a bandwidth from 0.11 to $4.86 \mathrm{~nm}$, as well as the group delay variation under strain, which corresponds to a tunable dispersion from 513.6 to $11.15 \mathrm{ps} / \mathrm{nm}$, respectively, with potential applications in both optical communications and microwave photonics systems.

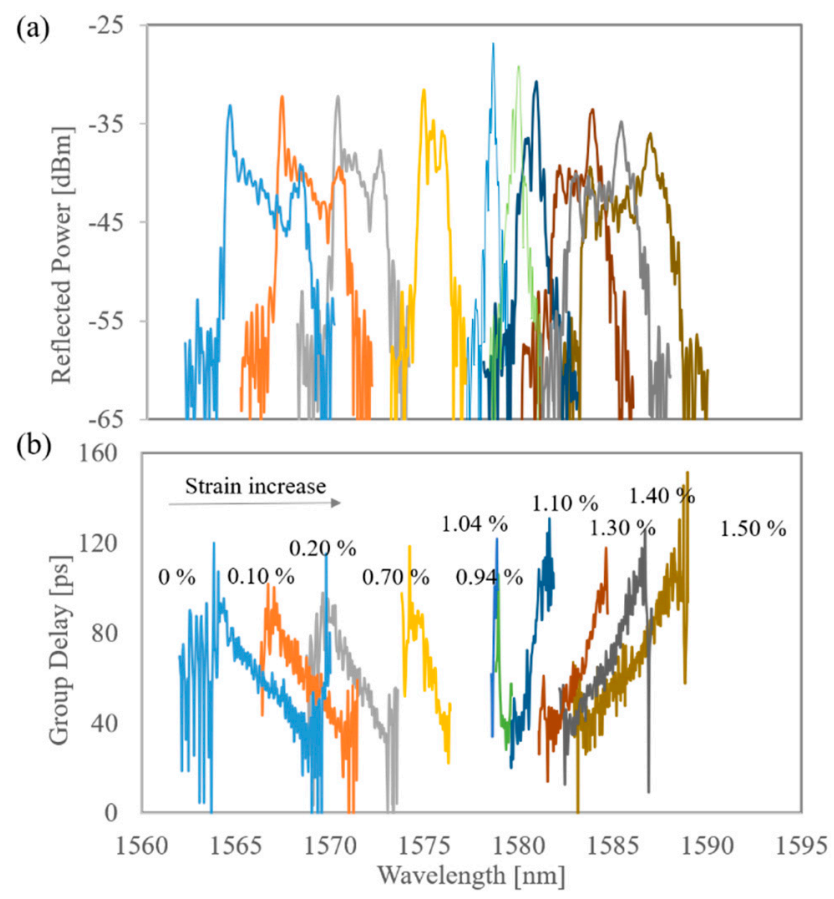

Figure 10. Tunable chirped FBG (a) reflected spectral power vs strain and (b) group delay vs strain; image adapted from [115].

Among the POF applications, due to polymer characteristics mentioned in the Introduction section of this paper, strain sensing is the most popular application. However, strain sensing under variable temperature and humidity conditions is always an issue for POF sensing. Min et al. [116] demonstrated that the effective bandwidth of the tunable chirped POFBG is highly dependent on the strain, and remains practically constant with temperature and humidity changes, which can be used in combination with wavelength measurement, as shown in Figure 11, to develop strain sensors under temperature- and humidity-variable environments. The strain sensitivity is $9.02 \pm 0.02 \mathrm{pm} / \mu \varepsilon$, which is higher than previous results [109] due to larger etching [92]. 

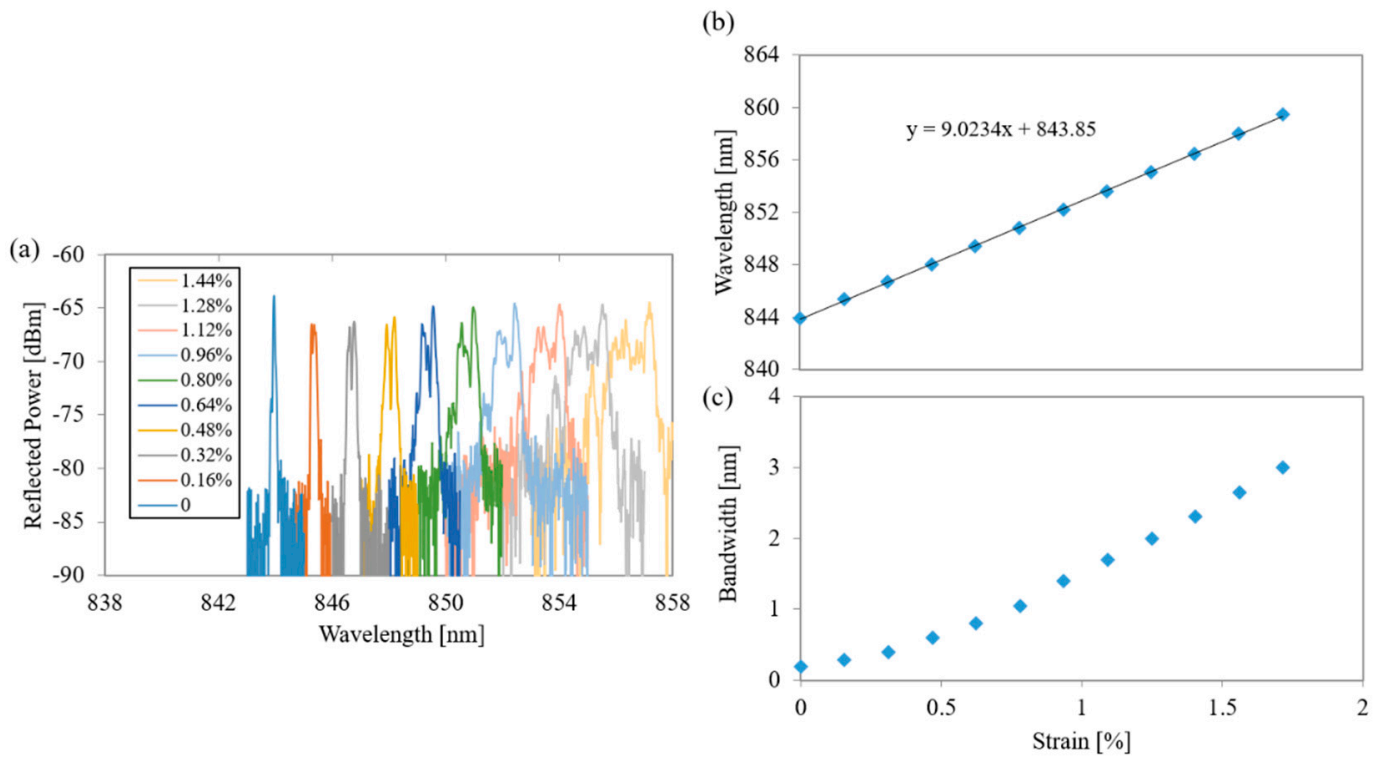

Figure 11. (a) Reflected spectral power vs strain, (b) wavelength shift vs strain, and (c) bandwidth vs strain; image adapted from [116].

One of the recent challenges for fiber optic temperature sensing is found in biomedical applications. An essential feature of these systems is the possibility of detecting temperature spatial distributions, also known as thermal maps [117]. A linearly chirped POFBG has been demonstrated as a semi-distributed temperature sensor capable of monitoring the temperature profile along the grating length for minimally invasive scenarios [118]. As shown in Figure 12, the chirped POFBG has been placed close to a radiofrequency applicator, with a tip inserted in situ of the target-the applicator connected to the Radio Frequency generator. The reflection spectrum was detected by Optical Backscatter Reflectometer (LUNA OBR 4600), and the temperature gradient was estimated with the Gaussian model. High sensitivity of chirped POFBG supports the detection of spatially non-uniform temperature by means of spectral reconstruction, which indicates that chirped FBG in $\mathrm{mPOF}$ can provide significant advantages for thermal detecting in bio-medical applications.

a)

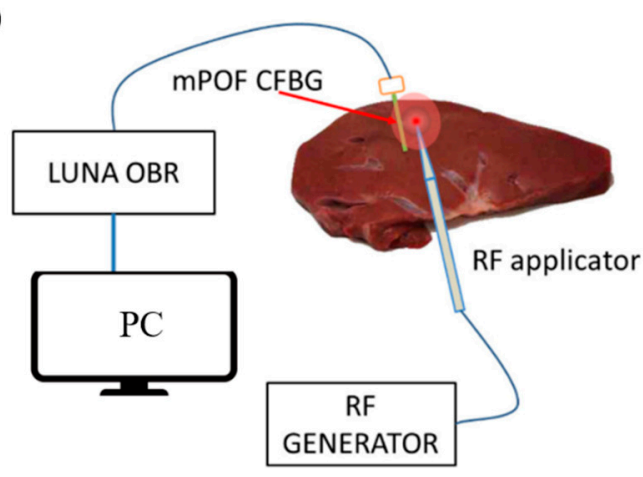

b)

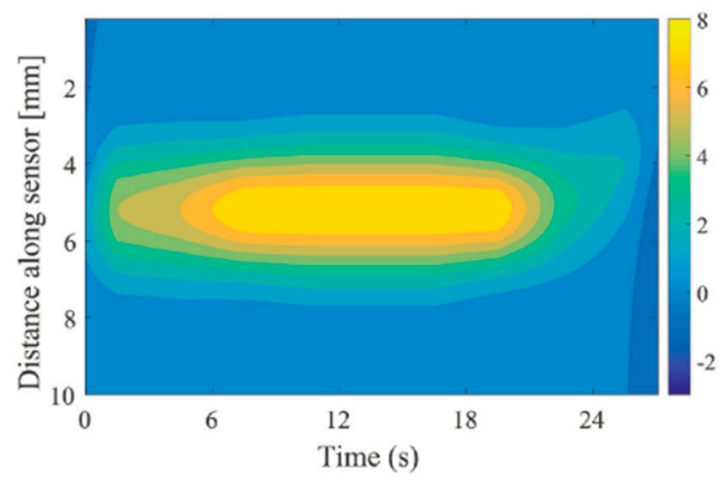

Figure 12. (a) Schematic of thermal ablation and (b) measurement of a Gaussian temperature gradient by using a chirped POFBG; image adapted from [118].

Furthermore, chirped POFBGs fabricated with chirped phase mask have been also demonstrated to provide accurate distributed pressure sensing [67]. The grating was subjected to pressure at various spatial position points of the grating, as shown in Figure 13, and the reflected spectral power showed a wavelength dip related to the pressed region, which can be used for different sensing applications. 
a)

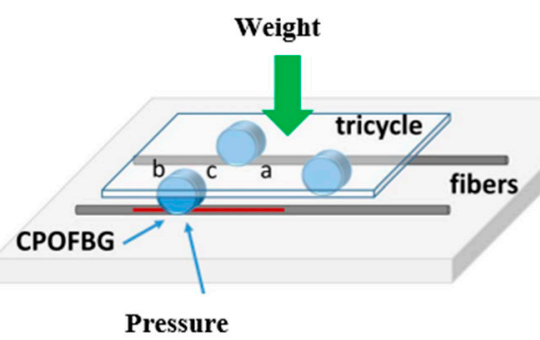

b)

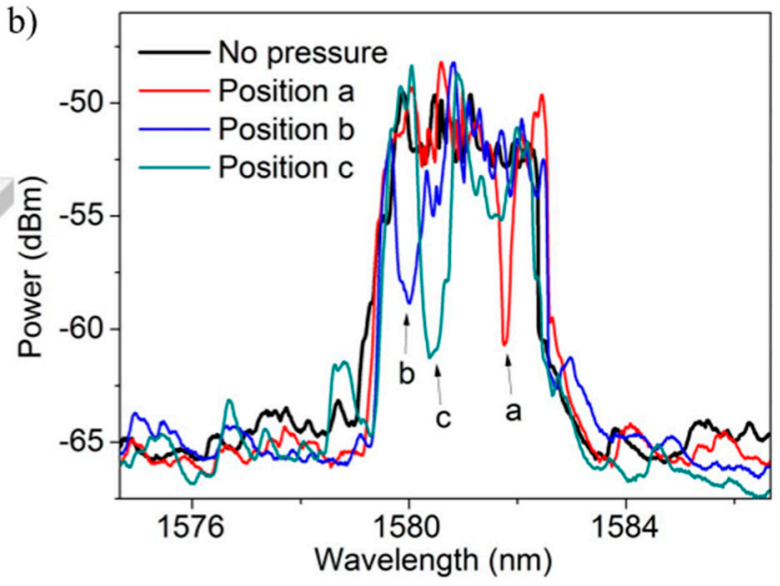

Figure 13. (a) Setup for applying pressure and (b) measured spectrum under point pressure; image adapted from [67].

Another interesting application is provided by health equipment for the dynamic monitoring of gait. An array of five FBGs inscribed in CYTOP fiber [119] was embedded in a cork insole, as shown in Figure 14. The advantages of POF (e.g., higher flexibility and robustness) enabled monitoring patients with higher body mass compared with similar systems based on silica fiber, with a mean sensitivity of $\sim 8.14 \mathrm{PM} / \mathrm{kPa}$, which is almost four times higher than silica FBGs $(\sim 2.51 \mathrm{pm} / \mathrm{kPa})$.

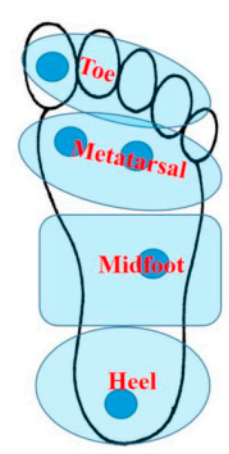

(a)

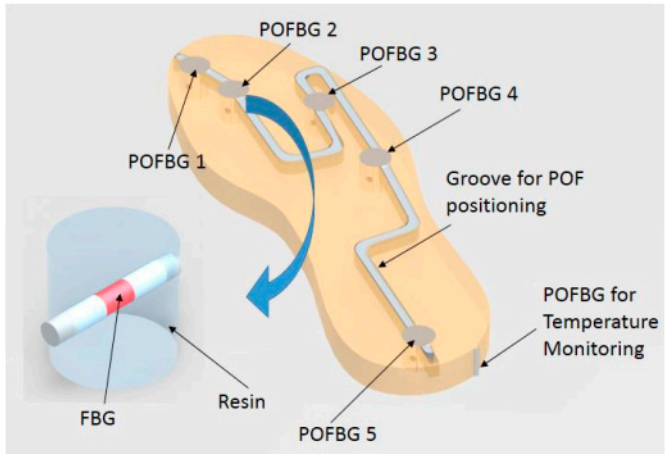

(b)

Figure 14. (a) Foot plantar area designation and sensing points and (b) FBG position in the cork insole; image from [120].

Surface plasmon resonance (SPR) is an accurate and reliable technique for determining the change of density at the interface between a dielectric medium and a metal, which has attracted huge attention for biochemical sensing in microfluidic systems. Hu et al. [120] reported the first excitation of SPR at near-infrared telecom wavelength with gold-coated POF tilted FBGs. They show the transmission dips corresponding to the orthogonally polarized modes, coupled in a 50-nm gold-coated $6^{\circ}$ tilted FBG immersed in a solution of refractive index 1.408. The transmission spectrum when the grating is immersed in different calibrated liquids covering a large SRI (sounding refractive index) range of $2.5 \times 10^{-2}$ RIU (refractive index unit). The refractometric sensitivity was measured up to $\sim 550 \mathrm{~nm} / \mathrm{RIU}$, with a wavelength shift as a function of the SRI value, which is suitable for in situ operation.

Finally, piezoelectric transducers of ultrasounds are widely used in the biomedical area, but the main drawback is their sensitivity to electromagnetic fields. Optical fibers are promising for replacing piezo electric transducers, with the benefit of electromagnetic interference immunity and with good sensor sensitivity and size for ultrasonic detection. POF shows better robustness and sensitivity to pressure than silica fiber, as required by ultrasound detectors. Broadway et al. [121] presented the first ultrasonic detection at 5, 10, and $15 \mathrm{MHz}$ by using a tilted FBG in commercial CYTOP fibers, as shown in Figure 15, which paves the way towards its eventual applications. 


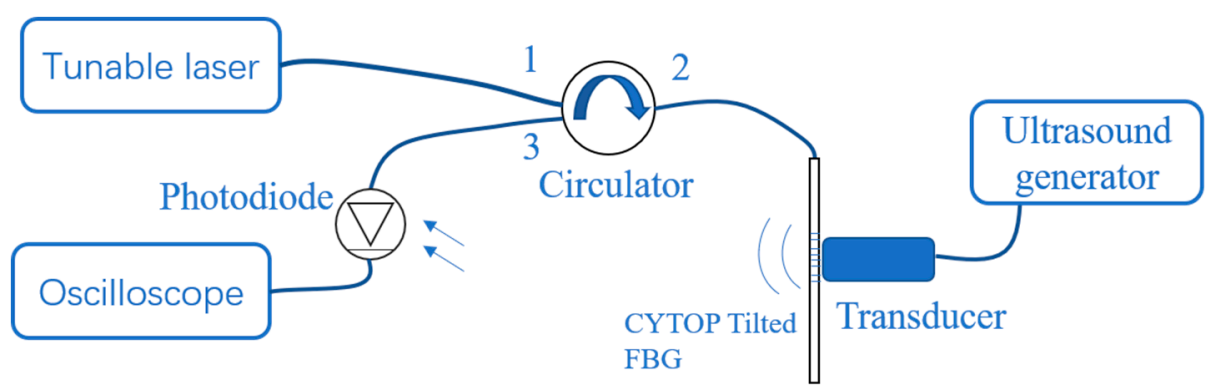

Figure 15. Ultrasonic detection setup.

\section{Conclusion and Outlook}

Significant progress has been obtained during recent years in POF grating devices fabrication and applications, in order to allow fast fabrication of POF grating devices under $248 \mathrm{~nm}$ and $266 \mathrm{~nm}$ wavelength UV, such as one short UV pulse (15 ns) for chirped POFBG fabrication. Besides the benefit of potential grating fabrication in the drawing tower, special grating structures also take advantage of the short irradiation time to reduce the stability requirements in the fabrication setup.

Besides humidity-, temperature-, and strain-sensitive devices as the main applications of uniform POF FBG, special grating devices open new perspectives. As the main relevant examples, this paper reviews chirped POFBGs for high-resolution thermal detection in the biomedical area, which show higher sensitivity and bio-compatibility than silica ones. In addition, tilted POF FBG for SPR sensing and tilted FBGs for high-resolution acoustic detection are promising for in situ operation. Furthermore, optical communication applications, such as dispersion compensation and slicing broadband sources for WDM systems, among others, will benefit from the POF advantages in the implementation of future indoor networks.

To conclude, POF gratings show attractive performance from the sensing area to the short-range optical communication area. However, as we know, most of the POFs for grating devices fabrication are homemade, which still need more time to make this technology mature for potential real applications; from this perspective, grating devices in commercial CYTOP POF are promising for real applications. More progress is required to achieve strong and stable devices in reduced-loss and low-price POFs.

Author Contributions: Writing—original draft preparation, R.M., B.O., and C.M.; writing—review and editing, B.O. and C.M.

Funding: This research was funded by Research Excellence Award Programme GVA PROMETEO 2017/103 and Fundação para a Ciência e a Tecnologia, I.P. (FCT) through the program UID/CTM/50025/2019, by the National Funds through the Fundação para a Ciência e a Tecnologia / Ministério da Educação e Ciência, and by the European Regional Development Fund under the PT2020 Partnership Agreement. This work is also funded by national funds (OE), through FCT, in the scope of the framework contract foreseen in the numbers 4, 5, and 6 of the article 23, of the Decree-Law 57/2016, of August 29, changed by Law 57/2017, of July 19, the Science Foundation of Heilongjiang Province of China (F2018026) and University Nursing Program for Young Scholars with Creative Talents in Heilongjiang Province (NPYSCT-2018012).

Acknowledgments: The authors acknowledge the supported by FCT, Research Excellence Award Programme GVA PROMETEO 2017/103, and the Science Foundation of Heilongjiang Province of China.

Conflicts of Interest: The authors declare no conflict of interest.

\section{References}

1. Webb, D.J. Fibre Bragg grating sensors in polymer optical fibres. Meas. Sci. Technol. 2015, 26, 092004. [CrossRef]

2. Prado, A.R.; Leal-Junior, A.G.; Marques, C.; Leite, S.; De Sena, G.L.; Machado, L.C.; Frizera, A.; Ribeiro, M.R.; Pontes, M.J. Polymethyl methacrylate (PMMA) recycling for the production of optical fiber sensor systems. Opit. Express 2017, 25, 71-80. [CrossRef] [PubMed] 
3. Markos, C.; Stefani, A.; Nielsen, K.; Rasmussen, H.K.; Yuan, W.; Bang, O. High-T TOPAS microstructured polymer optical fiber for fiber Bragg grating strain sensing at 110 degrees. Opt. Express 2013, 21, 4758-4765. [CrossRef]

4. Woyessa, G.; Fasano, A.; Markos, C.; Stefani, A.; Rasmussen, H.K.; Bang, O. Zeonex microstructured polymer optical fiber: Fabrication friendly fibers for high temperature and humidity insensitive Bragg grating sensing. Opt. Mater. Express 2017, 7, 286. [CrossRef]

5. Fasano, A.; Woyessa, G.; Stajanca, P.; Markos, C.; Stefani, A.; Nielsen, K.; Rasmussen, H.K.; Krebber, K.; Bang, O. Fabrication and characterization of polycarbonate microstructured polymer optical fibers for high-temperature-resistant fiber Bragg grating strain sensors. Opt. Mater. Express 2016, 6, 649. [CrossRef]

6. Gierej, A.; Vagenende, M.; Filipkowski, A.; Siwicki, B.; Buczynski, R.; Thienpont, H.; Van Vlierberghe, S.; Geernaert, T.; Dubruel, P.; Berghmans, F. Poly (D,L-lactic acid) (PDLLA) biodegradable and biocompatible polymer optical fiber. J. Lightwave Technol. 2019. [CrossRef]

7. Koike, Y.; Koike, K. Progress in low-loss and high-bandwidth plastic optical fibers. J. Polym. Sci. Part B Polym. Phys. 2011, 49, 2-17. [CrossRef]

8. Koike, Y.; Asai, M. The future of plastic optical fiber. NPG Asia Mater. 2009, 1, 22-28. [CrossRef]

9. Zubia, J.; Arrue, J. Plastic optical fibers: An introduction to their technological processes and applications. Opt. Fiber Technol. 2001, 7, 101-140. [CrossRef]

10. Polishuk, P. Plastic optical fibers branch out. IEEE Commun. Mag. 2006, 44, 140-148. [CrossRef]

11. Knight, J.C.; Birks, T.A.; Russell, P.S.J.; Atkin, D.M. All-silica single-mode optical fiber with photonic crystal cladding. Opt. Lett. 1997, 22, 484. [CrossRef] [PubMed]

12. Argyros, A. Microstructured polymer optical fibers. J. Lightwave Technol. 2009, 27, 1571-1579. [CrossRef]

13. Akande, K.O.; Popoola, W.O. Experimental Demonstration of Subband Index Techniques for m-CAP in Short-Range SI-POF Links. IEEE Photonics Technol. Lett. 2018, 30, 2155-2158. [CrossRef]

14. Vinogradov, J.; Kruglov, R.; Engelbrecht, R.; Ziemann, O.; Sheu, J.K.; Chi, K.L.; Wun, J.M.; Shi, J.W. GaN-based cyan light-emitting diode with up to $1-\mathrm{GHz}$ bandwidth for high-speed transmission over SI-POF. IEEE Photonics J. 2017, 9, 1-7. [CrossRef]

15. Sáez-Rodríguez, D.; Nielsen, K.; Bang, O.; Ortega, B. Compact multichannel demultiplexer for WDM-POF networks based on spatially overlapped FBGs. Electron. Lett. 2016, 52, 635-637. [CrossRef]

16. Li, C.-Y.; Lu, H.-H.; Wang, Y.-C.; Wang, Z.-H.; Su, C.-W.; Lu, Y.-F.; Tsai, W.-S. An 82-m 9 Gb/s PAM4 FSO-POF-UWOC Convergent System. IEEE Photonics J. 2019, 11, 1-9. [CrossRef]

17. Binh, P.H.; Trong, V.D. 500 MBIT/s OOK-NRZ transceiver for 50 m GI-POF using $100 \mathrm{MHz}$ RC-led. Microw. Opt. Technol. Lett. 2015, 57, 826-830. [CrossRef]

18. Aguirre, J.; Sánchez-Azqueta, C.; Guerrero, E.; Gimeno, C.; Celma, S. 3.125 Gbit/s CMOS transceiver for duobinary modulation over 50-m SI-POF channels. Electron. Lett. 2017, 53, 3-4. [CrossRef]

19. Li, X.; Bamiedakis, N.; Wei, J.; McKendry, J.J.; Xie, E.; Ferreira, R.; Gu, E.; Dawson, M.D.; Penty, R.V.; White, I.H. $\mu$ lED-Based Single-Wavelength Bi-directional POF Link with $10 \mathrm{~Gb} / \mathrm{s}$ Aggregate Data Rate. J. Lightwave Technol. 2015, 33, 3571-3576. [CrossRef]

20. Lin, C.Y.; Li, C.Y.; Lu, H.H.; Chang, C.H.; Peng, P.C.; Lin, C.R.; Chen, J.H. A hybrid CATV/16-QAM-OFDM in-house network over SMF and GI-POF/VLC transport. IEEE Photonics Technol. Lett. 2015, 27, 526-529. [CrossRef]

21. Gimeno, C.; Guerrero, E.; Sanchez-Azqueta, C.; Aguirre, J.; Aldea, C.; Celma, S. Multi-rate adaptive equalizer for transmission over up to 50-m SI-POF. IEEE Photonics Technol. Lett. 2017, 29, 587-590. [CrossRef]

22. Ishigure, T.; Nihei, E.; Yamazaki, S.; Kobayashi, K.; Koike, Y. 2.5Gbit/s 100m data transmission using graded-index polymer optical fibre and high-speed laser diode at 650nm wavelength. Electron. Lett. 1995, 31, 467-469. [CrossRef]

23. Koike, Y.; Inoue, A. High-Speed Graded-Index Plastic Optical Fibers and Their Simple Interconnects for 4K/8K Video Transmission. J. Lightwave Technol. 2016, 34, 1551-1555. [CrossRef]

24. Pinzón, P.J.; Pérez, I.; Vázquez, C. Visible WDM System for Real-Time Multi-Gb/s Bidirectional Transmission over 50-m SI-POF. IEEE Photonics Technol. Lett. 2016, 28, 1696-1699. [CrossRef]

25. Osahon, I.N.; Rajbhandari, S.; Popoola, W.O. Performance comparison of equalization techniques for SI-POF multi-gigabit communication with PAM-M and device non-linearities. J. Lightwave Technol. 2018, 36, 2301-2308. [CrossRef] 
26. Forni, F.; Shi, Y.; Tran, N.C.; Van Den Boom, H.P.A.; Tangdiongga, E.; Koonen, A.M.J. Multiformat wired and wireless signals over large-core plastic fibers for in-home network. J. Lightwave Technol. 2018, 36, 3444-3452.

27. Peters, K. Polymer optical fiber sensors-A review. Smart Mater. Struct. 2011, 20, 013002. [CrossRef]

28. Bilro, L.; Alberto, N.; Pinto, J.L.; Nogueira, R. Optical sensors based on plastic fibers. Sensors 2012, 12, 12184-12207. [CrossRef]

29. Durana, G.; Poisel, H.; Zubia, J.; Saez, I.; Gomez, J. Monitoring the vertical deflection of a flap rudder using a novel fibre optical strain sensor. IEEE Sens. J. 2009, 9,3-7. [CrossRef]

30. Babchenko, A.; Maryles, J. Graded-index plastic optical fiber for deformation sensing. Opt. Lasers Eng. 2007, 45, 757-760. [CrossRef]

31. Leal-Junior, A.G.; Frizera, A.; Marques, C.; Sánchez, M.R.A.; Botelho, T.R.; Segatto, M.V.; Pontes, M.J. Polymer optical fiber strain gauge for human-robot interaction forces assessment on an active knee orthosis. Opt. Fiber Technol. 2018, 41, 205-211. [CrossRef]

32. Leal-Junior, A.G.; Frizera, A.; Avellar, L.M.; Marques, C.; Pontes, M.J. Polymer Optical Fiber for In-Shoe Monitoring of Ground Reaction Forces during the Gait. IEEE Sens. J. 2018, 18, 2362-2368. [CrossRef]

33. Valencia-Jimenez, N.; Leal-Junior, A.; Avellar, L.; Vargas-Valencia, L.; Caicedo-Rodríguez, P.; Ramírez-Duque, A.A.; Lyra, M.; Marques, C.; Bastos, T.; Frizera, A. A Comparative Study of Markerless Systems Based on Color-Depth Cameras, Polymer Optical Fiber Curvature Sensors, and Inertial Measurement Units: Towards Increasing the Accuracy in Joint Angle Estimation. Electronics 2019, 8, 173. [CrossRef]

34. Aitkulov, A.; Tosi, D. Optical fiber sensor based on plastic optical fiber and smartphone for measurement of the breathing rate. IEEE Sens. J. 2019. [CrossRef]

35. Wong, Y.M.; Scully, P.J.; Bartlett, R.J.; Kuang, K.S.C.; Cantwell, W.J. Plastic optical fibre sensors for environmental monitoring: Biofouling and strain applications. Strain 2003, 39, 115-119. [CrossRef]

36. Teng, C.; Liu, H.; Deng, H.; Deng, S.; Yang, H.; Xu, R.; Chen, M.; Yuan, L.; Zheng, J. Liquid Level Sensor Based on a V-Groove Structure Plastic Optical Fiber. Sensors 2018, 18, 3111. [CrossRef]

37. Leal-Junior, A.G.; Frizera, A.; Marques, C.; Sanchez, M.R.A.; Dos Santos, W.M.; Siqueira, A.A.G.; Segatto, M.V.; Pontes, M.J. Polymer Optical Fiber for Angle and Torque Measurements of a Series Elastic Actuator's Spring. J. Lightwave Technol. 2018, 36, 1698-1705. [CrossRef]

38. Shan, M.; Min, R.; Zhong, Z.; Wang, Y.; Zhang, Y. Differential reflective fiber-optic angular displacement sensor. Opt. Laser Technol. 2015, 68, 124-128. [CrossRef]

39. Shan, M.; Min, R.; Zhong, Z.; Wang, Y.; Hao, B.; Zhang, Y. Differential transmissive fiber-optic distance sensor. Microw. Opt. Technol. Lett. 2014, 56, 1104-1107. [CrossRef]

40. Sequeira, F.; Duarte, D.; Bilro, L.; Rudnitskaya, A.; Pesavento, M.; Zeni, L.; Cennamo, N. Refractive index sensing with D-shaped plastic optical fibers for chemical and biochemical applications. Sensors 2016, 16, 2119. [CrossRef] [PubMed]

41. Teng, C.; Jing, N.; Yu, F.; Ding, Y.; Zheng, J. Refractive index sensor based on a multi-notched plastic optical fiber. Appl. Opt. 2017, 56, 1833-1838. [CrossRef]

42. Liehr, S.; Lenke, P.; Wendt, M.; Krebber, K.; Seeger, M.; Thiele, E.; Metschies, H.; Gebreselassie, B.; Munich, J.C. Polymer optical fiber sensors for distributed strain measurement and application in structural health monitoring. IEEE Sens. J. 2009, 9, 1330-1338. [CrossRef]

43. Mizuno, Y.; Nakamura, K. Brillouin Scattering in polymer optical fibers: Fundamental properties and potential use in sensors. Polymers 2011, 3, 886-898. [CrossRef]

44. Rao, Y.J. In-fibre Bragg grating sensors. Meas. Sci. Technol. 1997, 8, 355-375. [CrossRef]

45. Xiong, Z.; Peng, G.D.; Wu, B.; Chu, P.L. Highly Tunable Bragg Gratings in Single-Mode Polymer Optical Fibers. IEEE Photonics Technol. Lett. 1999, 11, 352-354. [CrossRef]

46. Dobb, H.; Webb, D.J.; Kalli, K.; Argyros, A.; Large, M.C.J.; van Eijkelenborg, M.A. Continuous wave ultraviolet light-induced fiber Bragg gratings in few- and single-mode microstructured polymer optical fibers. Opt. Lett. 2005, 30, 3296.

47. Sáez-Rodríguez, D.; Cruz, J.L.; Johnson, I.; Webb, D.J.; Large, M.C.J.; Argyros, A. Water diffusion into UV inscripted long period grating in microstructured polymer fiber. IEEE Sens. J. 2010, 10, 1169-1173. [CrossRef]

48. Johnson, I.P.; Kalli, K.; Webb, D.J. 827 nm Bragg grating sensor in multimode microstructured polymer optical fibre. Electron. Lett. 2010, 46, 3-4. [CrossRef]

49. Yuan, W.; Khan, L.; Webb, D.J.; Kalli, K.; Rasmussen, H.K.; Stefani, A.; Bang, O. Humidity insensitive TOPAS polymer fiber Bragg grating sensor. Opt. Express 2011, 19, 19731. [CrossRef] 
50. Koike, Y.; Ishigure, T.; Nihei, E. High-Bandwidth Graded-Index Polymer Optical Fiber. J. Lightwave Technol. 1995, 13, 1475-1489. [CrossRef]

51. Lacraz, A.; Polis, M.; Theodosiou, A.; Koutsides, C.; Kalli, K. Femtosecond Laser Inscribed Bragg Gratings in Low Loss CYTOP Polymer Optical Fiber. IEEE Photonics Technol. Lett. 2015, 27, 693-696. [CrossRef]

52. Theodosiou, A.; Hu, X.; Caucheteur, C.; Kalli, K. Bragg Gratings and Fabry-Perot Cavities in Low-Loss Multimode CYTOP Polymer Fiber. IEEE Photonics Technol. Lett. 2018, 30, 857-860. [CrossRef]

53. Leal-Junior, A.; Theodosiou, A.; Díaz, C.; Marques, C.; Pontes, M.J.; Kalli, K.; Frizera-Neto, A. Polymer Optical Fiber Bragg Gratings in CYTOP Fibers for Angle Measurement with Dynamic Compensation. Polymers 2018, 10, 674. [CrossRef]

54. Leal-junior, A.G.; Theodosiou, A.; Marques, C.; Pontes, M.J.; Kalli, K.; Frizera, A. Thermal Treatments and Compensation Techniques for the Improved Response of FBG Sensors in POFs. J. Lightwave Technol. 2018, 36, 3611-3617. [CrossRef]

55. Ishikawa, R.; Lee, H.; Lacraz, A.; Theodosiou, A.; Kalli, K.; Mizuno, Y. Pressure Dependence of Fiber Bragg Grating Inscribed in Perfluorinated Polymer Fiber. IEEE Photonics Technol. Lett. 2017, 29, 2167-2170. [CrossRef]

56. Leal-Junior, A.G.; Theodosiou, A.; Min, R.; Casas, J.; Díaz, C.R.; dos Santos, W.M.; Pontes, M.J.; Siqueira, A.A.G.; Marques, C.; Kalli, K.; Frizera, A. Quasi-Distributed Torque and Displacement Sensing on a Series Elastic Actuator_s Spring using FBG arrays inscribed in CYTOP Fibers. IEEE Sens. J. 2019. [CrossRef]

57. Koerdt, M.; Kibben, S.; Hesselbach, J.; Brauner, C.; Herrmann, A.S.; Vollertsen, F.; Kroll, L. Fabrication and Characterization of Bragg Gratings in a Graded-index Perfluorinated Polymer Optical Fiber. Procedia Technol. 2014, 15, 138-146. [CrossRef]

58. Min, R.; Ortega, B.; Leal-Junior, A.; Marques, C. Fabrication and Characterization of Bragg Grating in CYTOP POF at 600-nm Wavelength. IEEE Sens. Lett. 2018, 2, 1-4. [CrossRef]

59. Zheng, Y.; Bremer, K.; Roth, B. Investigating the strain, temperature and humidity sensitivity of a multimode graded-index perfluorinated polymer optical fiber with bragg grating. Sensors 2018, 18, 1436. [CrossRef] [PubMed]

60. Hu, X.; Pun, C.-F.J.; Tam, H.-Y.; Mégret, P.; Caucheteur, C. Highly reflective Bragg gratings in slightly etched step-index polymer optical fiber. Opt. Express 2014, 22, 18807. [CrossRef]

61. Hu, X.; Saez-Rodriguez, D.; Marques, C.; Bang, O.; Webb, D.J.; Mégret, P.; Caucheteur, C. Polarization effects in polymer FBGs: Study and use for transverse force sensing. Opt. Express 2015, 23, 4581. [CrossRef]

62. Chen, X.; Zhang, W.; Liu, C.; Hong, Y.; Webb, D.J. Enhancing the humidity response time of polymer optical fiber Bragg grating by using laser micromachining. Opt. Express 2015, 23, 25942. [CrossRef] [PubMed]

63. Rajan, G.; Noor, Y.M.; Liu, B.; Ambikairaja, E.; Webb, D.J.; Peng, G.D. A fast response intrinsic humidity sensor based on an etched singlemode polymer fiber Bragg grating. Sens. Actuators A Phys. 2013, 203, 107-111. [CrossRef]

64. Dobb, H.; Carroll, K.; Webb, D.J.; Kalli, K.; Komodromos, M.; Themistos, C.; Peng, G.D.; Argyros, A.; Large, M.C.J.; van Eijkelenborg, M.A.; et al. Grating based devices in polymer optical fibre. Proc. SPIE 2006, $6189,618901$.

65. Hu, X.; Pun, C.-F.J.; Tam, H.-Y.; Mégret, P.; Caucheteur, C. Tilted Bragg gratings in step-index polymer optical fiber. Opt. Lett. 2014, 39, 6835. [CrossRef] [PubMed]

66. Luo, Y.; Yan, B.; Zhang, Q.; Peng, G.D.; Wen, J.; Zhang, J. Fabrication of polymer optical fibre (POF) gratings. Sensors 2017, 17, 511. [CrossRef] [PubMed]

67. Marques, C.A.F.; Antunes, P.; Mergo, P.; Webb, D.J.; Andre, P. Chirped Bragg Gratings in PMMA Step-Index Polymer Optical Fiber. IEEE Photonics Technol. Lett. 2017, 29, 500-503. [CrossRef]

68. Canning, J. Properties of specialist fibres and bragg gratings for optical fiber sensors. J. Sens. 2009, 2009, 871580. [CrossRef]

69. Marques, C.A.F.; Webb, D.J.; Andre, P. Polymer optical fiber sensors in human life safety. Opt. Fiber Technol. 2017, 36, 144-154. [CrossRef]

70. Marques, C.; Leal-Junior, A.; Min, R.; Domingues, M.; Leitão, C.; Antunes, P.; Ortega, B.; André, P. Advances on Polymer Optical Fiber Gratings Using a KrF Pulsed Laser System Operating at 248 nm. Fibers 2018, 6, 13. [CrossRef]

71. Broadway, C.; Rui, M.; Leal Junior, A.G.; Marques, C.; Caucheteur, C. Towards commercial polymer fiber Bragg grating sensors: Review and applications. J. Lightwave Technol. 2018, 8724, 1. [CrossRef] 
72. Berghmans, F.; Geernaert, T.; Baghdasaryan, T.; Thienpont, H. Challenges in the fabrication of fibre Bragg gratings in silica and polymer microstructured optical fibres. Laser Photonics Rev. 2014, 8, 27-52. [CrossRef]

73. Nogueira, R.; Oliveira, R.; Bilro, L.; Heidarialamdarloo, J. New advances in polymer fiber Bragg gratings. Opt. Laser Technol. 2016, 78, 104-109. [CrossRef]

74. Stefani, A.; Stecher, M.; Town, G.E.; Bang, O. Direct writing of fiber bragg grating in microstructured polymer optical fiber. IEEE Photonics Technol. Lett. 2012, 24, 1148-1150. [CrossRef]

75. Li, Z.C.; Tam, H.Y.; Xu, L.X.; Zhang, Q.J. Fabrication of long-period gratings in poly(methyl methacrylate-co-methyl vinyl ketone-cobenzyl methacrylate)-core polymer optical fiber by use of a mercury lamp. Opt. Lett. 2005, 30, 1117-1119. [CrossRef] [PubMed]

76. Kowal, D.; Statkiewicz-Barabach, G.; Mergo, P.; Urbanczyk, W. Inscription of long period gratings using an ultraviolet laser beam in the diffusion-doped microstructured polymer optical fiber. Appl. Opt. 2015, 54, 6327-6333. [CrossRef]

77. Xingsheng, X.; Hai, M.; Qijin, Z. Properties of polarized laser-induced birefringent gratings in azobenzene-doped poly(methyl methecrylate) optical fibers. Opt. Commun. 2002, 204, 137-143. [CrossRef]

78. Hiscocks, M.P.; van Eijkelenborg, M.A.; Argyros, A.; Large, M.C.J. Stable imprinting of long-period gratings in microstructured polymer optical fibre. Opt. Express 2006, 14, 4644. [CrossRef]

79. Tomlinson, W.J.; Kaminow, I.P.; Chandross, E.A.; Fork, R.L.; Silfvast, W.T. Photoinduced Refractive Index Increase in Poly(methylmethacrylate) and its Applications. Appl. Phys. Lett. 1970, 16, 486-489. [CrossRef]

80. Yu, J.; Tao, X.; Tam, H. Trans-4-stilbenemethanol-doped photosensitive polymer fibers and gratings. Opt. Lett. 2004, 29, 156. [CrossRef] [PubMed]

81. Saez-Rodriguez, D.; Nielsen, K.; Bang, O.; Webb, D.J. Photosensitivity mechanism of undoped poly(methyl methacrylate) under UV radiation at $325 \mathrm{~nm}$ and its spatial resolution limit. Opt. Lett. 2014, 39, 3421-3424. [CrossRef] [PubMed]

82. Sáez-Rodríguez, D.; Nielsen, K.; Bang, O.; Webb, D.J. Time-dependent variation of fiber Bragg grating reflectivity in PMMA-based polymer optical fibers. Opt. Lett. 2015, 40, 1476-1479. [CrossRef] [PubMed]

83. Hu, X.; Kinet, D.; Mégret, P.; Caucheteur, C. Control over photo-inscription and thermal annealing to obtain high-quality Bragg gratings in doped PMMA optical fibers. Opt. Lett. 2016, 41, 2930-2933. [CrossRef] [PubMed]

84. Pospori, A.; Marques, C.A.F.; Bang, O.; Webb, D.J.; André, P. Polymer optical fiber Bragg grating inscription with a single UV laser pulse. Opt. Express 2017, 25, 9028. [CrossRef] [PubMed]

85. Yuan, W.; Stefani, A.; Bache, M.; Jacobsen, T.; Rose, B.; Herholdt-Rasmussen, N.; Nielsen, F.K.; Andresen, S.; Sørensen, O.B.; Hansen, K.S.; et al. Improved thermal and strain performance of annealed polymer optical fiber Bragg gratings. Opt. Commun. 2011, 284, 176-182. [CrossRef]

86. Hu, X.; Kinet, D.; Chah, K.; Pun, C.-F.J.; Tam, H.-Y.; Caucheteur, C. Bragg grating inscription in PMMA optical fibers using 400-nm femtosecond pulses. Opt. Lett. 2017, 42, 2794. [CrossRef] [PubMed]

87. Luo, Y.; Li, Z.; Zheng, R.; Chen, R.; Yan, Q.; Zhang, Q.; Peng, G.; Zou, G.; Ming, H.; Zhu, B. Birefringent azopolymer long period fiber gratings induced by $532 \mathrm{~nm}$ polarized laser. Opt. Commun. 2009, 282, 2348-2353. [CrossRef]

88. Baum, A.; Scully, P.J.; Basanta, M.; Thomas, C.L.P.; Fielden, P.R.; Goddard, N.J.; Perrie, W.; Chalker, P.R. Photochemistry of refractive index structures in poly(methyl methacrylate) by femtosecond laser irradiation. Opt. Lett. 2007, 32, 190-192. [CrossRef] [PubMed]

89. Liu, H.Y.; Peng, G.D.; Chu, P.L.; Koike, Y.; Watanabe, Y. Photosensitivity in low-loss perfluoropolymer(CYTOP)fibre material. Electron. Lett. 2001, 37, 347-348. [CrossRef]

90. Liu, H.Y.; Peng, G.D.; Chu, P.L. Polymer fiber Bragg gratings with 28-dB transmission rejection. IEEE Photonics Technol. Lett. 2002, 14, 935-937. [CrossRef]

91. Liu, H.B.; Liu, H.Y.; Peng, G.D.; Chu, P.L. Novel Growth Behaviors of Fiber Bragg Gratings in Polymer Optical Fiber under UV Irradiation with Low Power. IEEE Photonics Technol. Lett. 2004, 16, 159-161. [CrossRef]

92. Rajan, G.; Yusof, M.; Noor, M.; Lovell, N.H.; Ambikaizrajah, E.; Farrell, G.; Peng, G. Polymer micro-fiber Bragg grating. Opt. Lett. 2013, 38, 38-41. [CrossRef] [PubMed]

93. Sáez-Rodríguez, D.; Nielsen, K.; Rasmussen, H.K.; Bang, O.; Webb, D.J. Highly photosensitive polymethyl methacrylate microstructured polymer optical fiber with doped core. Opt. Lett. 2013, 38, 3769. [CrossRef]

94. Bundalo, I.-L.; Nielsen, K.; Markos, C.; Bang, O. Bragg grating writing in PMMA microstructured polymer optical fibers in less than 7 minutes. Opt. Express 2014, 22, 5270. [CrossRef] [PubMed] 
95. Kowal, D.; Statkiewicz-Barabach, G. Microstructured polymer optical fiber for long period gratings fabrication using an ultraviolet laser beam. Opt. Lett. 2014, 39, 2242-2245. [CrossRef] [PubMed]

96. Oliveira, R.; Bilro, L.; Nogueira, R. Bragg gratings in a few mode microstructured polymer optical fiber in less than 30 seconds. Opt. Express 2015, 23, 10181. [CrossRef] [PubMed]

97. Min, R.; Ortega, B.; Nielsen, K.; Bang, O.; Marques, C. Bragg Grating Inscription With Low Pulse Energy in Doped Microstructured Polymer Optical Fibers. IEEE Sens. Lett. 2018, 2, 2-5. [CrossRef]

98. Min, R.; Ortega, B.; Hu, X.; Broadway, C.; Caucheteur, C.; Pun, C.F.J.; Tam, H.Y.; Antunes, P.; Marques, C. Bragg gratings inscription in TS-doped PMMA POF by using 248-nm KrF pulses. IEEE Photonics Technol. Lett. 2018, 30, 1609-1612. [CrossRef]

99. Luo, Y.; Zhang, Q.; Liu, H.; Peng, G.-D. Gratings fabrication in benzildimethylketal doped photosensitive polymer optical fibers using $355 \mathrm{~nm}$ nanosecond pulsed laser. Opt. Lett. 2010, 35, 751-753. [CrossRef]

100. Peng, G.D.; Xiong, Z.; Chu, P.L. Photosensitivity and gratings in dye-doped polymer optical fibers. Opt. Fiber Technol. 1999, 5, 242-251. [CrossRef]

101. Hu, X.; Woyessa, G.; Kinet, D.; Janting, J.; Nielsen, K.; Bang, O.; Caucheteur, C. BDK-doped core microstructured PMMA optical fiber for effective Bragg grating photo-inscription. Opt. Lett. 2017, 42, 2209. [CrossRef] [PubMed]

102. Bonefacino, J.; Tam, H.-Y.; Glen, T.S.; Cheng, X.; Pun, C.-F.J.; Wang, J.; Lee, P.-H.; Tse, M.-L.V.; Boles, S.T. Ultra-fast polymer optical fibre Bragg grating inscription for medical devices. Light Sci. Appl. 2018, 7, 17161. [CrossRef] [PubMed]

103. Pereira, L.; Min, R.; Hu, X.; Caucheteur, C.; Bang, O.; Ortega, B.; Marques, C.; Antunes, P.; Pinto, J.L. Polymer optical fiber Bragg grating inscription with a single Nd:YAG laser pulse. Opt. Express 2018, 26, 18096. [CrossRef] [PubMed]

104. Marques, C.A.F.; Min, R.; Leal, A.; Antunes, P.; Fasano, A.; Woyessa, G.; Nielsen, K.; Rasmussen, H.K.; Ortega, B.; Bang, O. Fast and stable gratings inscription in POFs made of different materials with pulsed 248 nm KrF laser. Opt. Express 2018, 26, 272-281. [CrossRef] [PubMed]

105. Ortega, B.; Min, R.; Sáez-Rodríguez, D.; Mi, Y.; Nielsen, K.; Bang, O. Bandpass transmission filters based on phase shifted fiber Bragg gratings in microstructured polymer optical fibers. Proc. SPIE 2017, 10232, 1023209.

106. Min, R.; Marques, C.; Bang, O.; Ortega, B. Moiré phase-shifted fiber Bragg gratings in polymer optical fibers. Opt. Fiber Technol. 2018, 41, 78-81. [CrossRef]

107. Pereira, L.M.; Pospori, A.; Antunes, P.; Domingues, M.F.; Marques, S.; Bang, O.; Webb, D.J.; Marques, C.A.F. Phase-Shifted Bragg Grating Inscription in PMMA Microstructured POF Using 248-nm UV Radiation. J. Lightwave Technol. 2017, 35, 5176-5184. [CrossRef]

108. Liu, H.; Liu, H.; Peng, G.; Whitbread, T.W. Tunable dispersion using linearly chirped polymer optical fiber Bragg gratings with fixed center wavelength. IEEE Photonics Technol. Lett. 2005, 17, 411-413.

109. Min, R.; Ortega, B.; Marques, C. Fabrication of tunable chirped mPOF Bragg gratings using a uniform phase mask. Opt. Express 2018, 26, 4411-4420. [CrossRef] [PubMed]

110. Min, R.; Ortega, B.; Marques, C. Tunable chirped fiber bragg gratings in mPOF. In Proceedings of the Bragg Gratings, Photosensitivity and Poling in Glass Waveguides and Materials 2018, Zurich, Switzerland, 2-5 July 2018. Volume Part F98-B.

111. Min, R.; Ortega, B.; Broadway, C.; Caucheteur, C.; Woyessa, G.; Bang, O.; Antunes, P.; Marques, C. Hot water-assisted fabrication of chirped polymer optical fiber Bragg gratings. Opt. Express 2018, 26, 34655. [CrossRef] [PubMed]

112. Lwin, R.; Argyros, A.; Leon-Saval, S.G.; Large, M.C.J. Strain sensing using long period gratings in microstructured polymer optical fibres. Proc. SPIE 2011, 7753, 775396.

113. Min, R.; Marques, C.; Nielsen, K.; Bang, O.; Ortega, B. Fast Inscription of Long Period Gratings in Microstructured Polymer Optical Fibers. IEEE Sens. J. 2018, 18, 1919-1923. [CrossRef]

114. Statkiewicz-barabach, G.; Kowal, D.; Szczurowski, M.K.; Mergo, P.; Urbanczyk, W. Hydrostatic Pressure and Strain Sensitivity of Long Period Grating Fabricated in Polymer Microstructured Fiber. IEEE Photonics Technol. Lett. 2013, 25, 496-499. [CrossRef]

115. Min, R.; Korganbayev, S.; Moladi, C.; Broadway, C.; Hu, X.; Caucheteur, C.; Bang, O.; Antunes, P.; Tosi, D.; Marques, C.; et al. Largely tunable dispersion chirped polymer FBG. Opt. Lett. 2018, 43, 5106-5109. [CrossRef] [PubMed] 
116. Min, R.; Ortega, B.; Broadway, C.; Hu, X.; Caucheteur, C.; Bang, O.; Antunes, P.; Marques, C. Microstructured PMMA POF chirped Bragg gratings for strain sensing. Opt. Fiber Technol. 2018, 45, 330-335. [CrossRef]

117. Tosi, D.; Schena, E.; Molardi, C.; Korganbayev, S. Fiber optic sensors for sub-centimeter spatially resolved measurements: Review and biomedical applications. Opt. Fiber Technol. 2018, 43, 6-19. [CrossRef]

118. Korganbayev, S.; Min, R.; Jelbuldina, M.; Hu, X.; Caucheteur, C.; Bang, O.; Ortega, B.; Marques, C.; Tosi, D. Thermal Profile Detection Through High-Sensitivity Fiber Optic Chirped Bragg Grating on Microstructured PMMA Fiber. J. Lightwave Technol. 2018, 36, 4723-4729. [CrossRef]

119. Vilarinho, D.; Theodosiou, A.; Leitão, C.; Leal-Junior, A.G.; de Fátima Domingues, M.; Kalli, K.; André, P.; Antunes, P.; Marques, C. POFBG-embedded cork insole for plantar pressure monitoring. Sensors 2017, 17, 2924. [CrossRef] [PubMed]

120. Hu, X.; Mégret, P.; Caucheteur, C. Surface plasmon excitation at near-infrared wavelengths in polymer optical fibers. Opt. Lett. 2015, 40, 3998. [CrossRef] [PubMed]

121. Broadway, C.; Kalli, K.; Theodosiou, A.; Zubel, M.; Sugden, K.; Megret, P.; Caucheteur, C. L-band CYTOP Bragg gratings for ultrasound sensing. Proc. SPIE 2018, 10681, 1068109.

(C) 2019 by the authors. Licensee MDPI, Basel, Switzerland. This article is an open access article distributed under the terms and conditions of the Creative Commons Attribution (CC BY) license (http://creativecommons.org/licenses/by/4.0/). 